\title{
O que está por trás da avaliação das redações do vestibular?
}

\section{What is behind papers evaluation of "vestibular"?}

\author{
Erasmo Gruginski* \\ Iara Benquerer Costa** \\ Luís Gonçales Bueno de Camargo**** \\ Paulo Astor Soethe ${ }^{* * * *}$ \\ Teresa Cristina Wachowicz ${ }^{* * * * *}$
}

\begin{abstract}
RESUMO
Nosso objetivo, neste texto, é apresentar um relato de experiências de correção das redações do processo seletivo para a UFPR de 2003. Mais do que uma abordagem essencialmente teórica sobre questões lingüísticas, que envolvem avaliação de textos, o trabalho revela a metodologia adotada no processo avaliativo, que apresentou resultados positivos.

Palavras-chave: redação, avaliação, vestibular.
\end{abstract}

\begin{abstract}
Our objective in this article is to report our experience in rating written texts, which were part of the Federal University of Paraná entrance examination

* Professor Doutor do DELEM/UFPR. erasmo@ nethra.nc.ufpr.br

** Professora Doutora do DLLCV/UFPR. iarabemq@ufpr.br

**** Professor Doutor do DLLCV/UFPR. luis@coruja.humanas.ufpr.br

***** Professor Doutor do DELEM/UFPR. soethe@bsi.com.br

******* Professora Doutora do DLLCV/UFPR. tecaw@terra.com.br
\end{abstract}


for the year 2003. More than a theoretical discussion of linguistic issues in text rating, the article presents the methodology used in the evaluation process, which reached positive results.

Key-words: writing, evaluation, college entrance examination.

\section{Introdução}

O processo de avaliação de redações de vestibular certamente requer concepção teórica e postura metodológica diferentes da avaliação de produção escrita de alunos em sala de aula ou em ambientes didáticos microlocalizados. Por envolver um grande número de textos e corretores, e por se tratar de um exame classificatório de grandes conseqüências para os candidatos, devem ser tomados todos os cuidados para minimizar a variabilidade própria de testes desta natureza. No vestibular de 2003 da UFPR, por exemplo, do número total de candidatos (52.448), foram "peneirados" 26.529 em função, inclusive, da nota zero em uma das provas objetivas. Os textos por eles produzidos foram avaliados por 40 corretores. Para evitar injustiças, uma situação como essas requer a adoção de procedimentos para fazer frente às principais fontes de variabilidade, que são a ausência de critérios, a diferença de rigor na aplicação dos critérios e as inconsistências individuais originárias de fatores como cansaço, desatenção, preconceitos etc.

O primeiro passo, portanto, é a definição de critérios e a calibragem das notas, em processo anterior ao início da correção propriamente dita. O simples fato de haver uma discussão coletiva dos critérios não assegura que os corretores vão se ater a eles de maneira uniforme. É necessário que haja uma ou mais "rodadas" de correção para ver, na prática, se os critérios estão funcionando adequadamente e se todos os corretores estão se comportando de forma consistente. Nessa etapa, as notas ou conceitos de todos os corretores devem ser constantemente monitorados e comparados.

Além dos dados quantitativos, a prova de redação da UFPR - absolutamente original em relação a outras de todo o país - distribui quatro ou cinco questões específicas, que avaliam diferentes domínios ou habilidades de leitura e produção escrita. Quer dizer, no lugar de produzir extensos textos de caráter geralmente dissertativo, como nas propostas de outros 
vestibulares, os candidatos produzem pequenos textos de modo a revelar suas habilidades específicas de escrita: o resumo, a carta, a transposição de discurso direto-indireto, a tradução em prosa de dados numéricos, a análise de textos literários, a argumentação, a publicidade etc. (MEC/SEF, 1999; BRANDÃO 2000). Com um trabalho especialmente direcionado a esse modelo de prova desde 1996, acreditamos poder avaliar diretamente habilidades de escrita pertinentes às experiências acadêmicas dos futuros alunos da universidade.

E como pensar nos critérios de correção dos textos do nosso vestibular? Inicialmente, como são questões diferentes, que avaliam habilidades de escrita diferentes, os corretores são divididos em equipes, cada uma com aproximadamente 10 corretores responsáveis por uma só questão. Há corretores, por exemplo, que, em razão de sua área de pesquisa, direcionamse melhor a uma questão de literatura; outros, a uma questão de texto argumentativo, e assim por diante. Cada equipe, então, promove uma ampla discussão, por meio da leitura prévia de um conjunto de 100 redações, para a definição de critérios que nortearão a avaliação de sua questão.

E é justamente aí que está o principal segredo da correção de textos do vestibular: cada questão da prova requer domínio de escrita de um tipo específico de texto; cada tipo de texto, ou gênero, tem suas intenções específicas; e cada intenção textual requer uma estrutura e uma situação enunciativa próprias. Ora, a discussão de critérios por parte dos corretores deve acompanhar esse raciocínio básico, que é teórico: o corretor deve ter domínio do tipo de texto referente à sua questão para discutir e definir as características textuais balizadoras da correção. Por exemplo, um texto que transcreve em prosa os dados numéricos de gráficos e/ou tabelas não pode ter traços de subjetividade ou inserções opinativas; um texto que se pretende argumentativo não pode ser simplesmente descritivo etc.

E como fica a atribuição de notas? É evidente que os critérios teóricos de cada questão, definidos pela discussão em equipe (é importante frisar), são paralelamente construídos com os critérios de atribuição de notas. Neste ano de 2003, a nota se baseou numa escala de números inteiros de 0 (zero) a 6 (seis), com dois momentos de conceituação: no primeiro momento, relativo à avaliação da adequação à proposta, a discriminação básica da nota variava entre os conceitos insuficiente, regular e bom; no segundo momento, relativo à avaliação de domínio de escrita, a discriminação secundária da nota era então granularizada e variava entre as notas 1, 2, 3, 4 e 5. Os extremos da escala ficaram assim definidos: o 0 (zero) equivale ao texto 
que não atende minimamente à proposta apresentada no enunciado da questão, e o 6 (seis) equivale ao texto excelente, com um tratamento do tema e um domínio de escrita bem superiores ao conjunto dos candidatos.

A primeira avaliação toma como base os critérios contextuais, ou seja, os critérios que encaixam o texto em seu gênero ou tipo específico (a construção argumentativa para o texto opinativo; as opções persuasivas para o texto publicitário etc.); já a segunda avaliação, toma como base os critérios lingüísticos, desde a estruturação (coerência e coesão) (FÁVERO 1995; KOCH 2002a, b) até o domínio de escrita padrão (acentuação, concordância etc.).

Além dessas duas avaliações, que sinalizam uma discriminação conceitual básica e uma discriminação secundária por notas, cada texto é lido novamente por um segundo corretor (obviamente, da mesma equipe), que procede da mesma forma que o primeiro: dois momentos de avaliação, um com discriminação conceitual e outro com discriminação de nota. Se houver diferença superior a dois pontos entre as notas dos dois corretores, ainda um terceiro corretor faz a sua leitura para resolver as discrepâncias durante a correção.

Os textos foram, então, avaliados a partir da seguinte escala:

Mediante uma metodologia de correção desmembrada em dois momentos de avaliação, bem como Por meio de uma escala de 0 (zero) a 6 (seis) - e não mais de 0 a 10 -, acreditamos ter desenvolvido um processo avaliativo que efetivamente discrimine os textos na escala, a partir de critérios estabelecidos pelos próprios membros de cada equipe. Além disso, por meio de uma dinâmica de correção que envolve discussões monitoradas sobre os critérios e correspondentes notas, leituras de dois corretores (e até de um terceiro), bem como por um de controle estatístico diário sobre as notas durante o período de correção, acreditamos ter viabilizado um processo avaliativo, que controle as interferências subjetivas dos corretores no momento de atribuir nota (cansaço, biorritmo, estado emocional etc.), que qualquer professor de língua conhece muito bem.

Uma escala menor permite que os corretores utilizem pontos de referência mais claros, o que deve render maior consistência de resultados. Os pontos de discriminação básica (Insuficiente, Regular, Bom) atuam como âncoras e permitem situar as avaliações num espaço mais claramente definido. Em uma escala de 0 a 10, há uma dificuldade maior de discriminar consistentemente os textos quando as diferenças entre um ponto e outro da escala são tão pequenas. 
As seções seguintes apresentarão, de forma geral, os critérios de correção definidos pelos corretores e respectivas equipes. A prova de 2003, nesse sentido, teve quatro questões: uma de texto argumentativo (questão 21), uma de resumo (questão 22), uma de texto de divulgação (questão 23) e outra de literatura (questão 24), envolvendo a leitura de um dos livros da lista de obras literárias requerida pela prova. As curiosidades teóricas, relativas aos diferentes tipos textuais requeridos em 2003, podem ser agora sanadas.

\section{A análise das questões}

\section{Questão 21}

A primeira questão, a 21, teve como proposta a construção de um texto argumentativo, baseado em informações diversas sobre o tema de acidentes de trânsito no Brasil, principalmente os que envolvem jovens. Confira:

21 - Segundo o Mapa da Violência 3, da UNESCO, publicado este ano, na faixa que vai de 15 a 24 anos, em 2000, morreram 6.414 jovens em decorrência de acidentes de transporte no Brasil - o que representa 21,8\% do total de mortes pela mesma causa naquele ano. De acordo com dados da CET (Companhia de Engenharia de Tráfego), de 1999, nas colisões fatais em São Paulo, 40\% dos mortos estavam na faixa etária de 16 a 25 anos. "A maior incidência de acidentes com pessoas dessa faixa etária ocorre das $18 \mathrm{~h}$ de sexta-feira até domingo de manhã, sendo o pico na virada de sábado para domingo", diz José Borges de Carvalho Filho, superintendente do Centro de Treinamento e Educação de Trânsito da CET.

Agora veja os dados gerais da cidade de São Paulo: 
WACHOWICZ, T. C. et. al. O que está atrás da avaliação...

\begin{tabular}{|c|c|c|}
\hline Acada2,6min & $\rightarrow$ & éregistradoumacidente \\
\hline Acada9,4min & $\rightarrow$ & morreumcapantedevéádo \\
\hline Acada11,7min & $\rightarrow$ & umapessoaficaferica \\
\hline Acada21,1min & $\rightarrow$ & aconteceumacidantecomútimas rãopedestres \\
\hline Acada443min & $\rightarrow$ & acotece umatroplanato \\
\hline Acada46,4min & $\rightarrow$ & umpedestreéferido \\
\hline
\end{tabular}

(Fonte: CET- Companhia de Engenharia de Tráfego)

(Adaptado de: Folha de S. Paulo, Folhateen, 07 out. 2002.)

Com base nas informações acima, elabore um texto de até 10 linhas em que você prove a necessidade de mudança desse quadro.

A proposta está vinculada à expressão "prove a necessidade de mudança desse quadro" (do enunciado), pois o texto argumentativo define-se justamente pela prova ou sustentação de uma tese a partir de argumentos a ela relacionados (PERELMAN; OLBRECHTS-TYTECA, 1996). O comando da questão, nesse sentido, já dá a tese que o candidato deve provar: a de que há necessidade de mudança no quadro de acidentes de trânsito. E o candidato deve utilizar-se das informações apresentadas pela questão para a construção de argumentos que a sustentem.

Logo, grosso modo, os textos aqui considerados bons são os que realmente se utilizam dos dados do enunciado para a construção de evidências (numéricas) para uma argumentação consistente. $\mathrm{O}$ texto 1 abaixo, com conceito bom, ficou com nota 5 (cinco):

O grande número de mortes ocorridas em acidente de trânsito no Brasil expõe a necessidade da elaboração de leis e medidas mais rígidas para reverter esse quadro. Segundo dados da UNESCO, do total de mortes causadas por acidentes de trânsito, $21,8 \%$ são de jovens entre 15 e 24 anos, o que representa 6.414 falecimentos. Segundo a Companhia de Engenharia de Tráfego, só na cidade de São Paulo, a cada 2,6 minutos um acidente é registrado, sendo que morre um ocupante de veículo a cada 9,4 minutos. Se esses índices já são altíssimos apenas para uma cidade brasileira, imagine os dados referentes a toda a nação.

Texto 1: redação prototípica para o conceito BOM, com nota 5, da questão 21. 
No outro extremo da escala de avaliação, estão os textos considerados nulos (o que equivale à nota zero), que não só deixam de considerar os dados apresentados na questão como não respondem à proposta argumentativa. Ou seja, são textos que se desviam inteiramente do tema e/ ou da proposta de tipo textual requerido, além de, via de regra, apresentarem problemas sérios de escrita:

Programas de conscientização, estamos tendo diversos, por isso a questão de a violência ter um índice tão grande de mortes, principalmente entre os jovens se dá pela irresponsabilidade, de uma geração "carente" de uma identidade e de valores, pois não respeitam a própria vida, quem dirá a dos outros, já é reflexo de uma educação de base "sucateada" e a absorção do lixo, dos lixos dos Estados Unidos e principalmente impunidade.

Texto 2: redação prototípica para o conceito NULO (nota 0 ), da questão 21.

O conceito regular da questão 21 ficou por conta da tendência da grande maioria dos textos: a elaboração de uma síntese dos dados presentes no enunciado. Se esse tipo de texto mostrava um bom domínio de estruturação textual e de escrita, a nota poderia subir para 4; ao contrário, se o texto apresentava vários e sérios problemas de escrita, a nota abaixava para 2, como foi o caso do texto 3:

Com base nos dados apresentados pelo CET (Companhia de Engenharia de Tráfego) nota-se um grande número de jovens que morrem decorrentes de acidentes de trânsito e esse quadro tem que mudar. Morrer no trânsito é uma falta de responsabilidade (não em todos os casos), estar em alta velocidade, distraido conversando ou principalmente bebado pode ser fatal. Isso reproduz no cotidiano o que o CET constatou que a maioria dos acidentes ocorrem na sexta-feira depois das 18 h até o domingo de manhã, onde e quando as pessoas saem se divertem e esquecem dos compromissos.

Texto 3: redação prototípica para o conceito REGULAR, com nota 2, da questão 21 . 
WACHOWICZ, T. C. et. al. O que está atrás da avaliação...

\section{Questão 22}

A questão 22, por sua vez, teve como objetivo avaliar a capacidade de leitura e redação dos candidatos a partir da elaboração de um resumo, texto que deveria expor as afirmações mais relevantes do texto original, com a explicitação das suas relações lógico-semânticas, em uma seleção compatível com o espaço de 10 linhas (PLATÃO; FIORIN,1993). O comando apresenta um texto adaptado de uma entrevista publicada na revista Superinteressante com uma abordagem polêmica sobre a questão do meio ambiente:

22 -Elabore um resumo de até 10 linhas do texto abaixo.

É tudo mentira

Há três anos, quando decidiu escrever um livro questionando os dados que sustentam as causas ecológicas, o estatístico dinamarquês Bjorn Lomborg mal poderia imaginar a fúria que seu trabalho iria despertar entre os ambientalistas. Best-seller na Europa e nos Estados Unidos, seu livro $\mathrm{O}$ ambientalista cético (inédito no Brasil) defende que, tanto do ponto de vista ambiental quanto do social, o planeta nunca esteve tão bem - e que a tendência é só melhorar. Computando análises estatísticas de governos, da ONU e de outros institutos de pesquisa, Lomborg afirma que a humanidade não precisa se alarmar com o efeito estufa, os buracos na camada de ozônio, a chuva ácida ou o desmatamento da Amazônia - para citar apenas algumas das causas dos ecologistas. Ele acredita que os governos e a iniciativa privada já estão agindo para corrigir os estragos cometidos contra a natureza e acusa de apocalípticos e inconsistentes os que discordam da sua análise. Eis algumas declarações polêmicas de Lomborg: "No caso de países emergentes, garantir as necessidades básicas da população produzir bastante comida - pode ser mais importante do que o meio ambiente. É verdade que o número de famintos vem caindo no mundo, mas ainda precisa cair mais. De acordo com a ONU, em 2010 ainda haverá 680 milhões de famintos no planeta. E, além de tirar as pessoas da pobreza, é preciso garantir saúde e educação. Apenas quando você não tem que se preocupar em conseguir sua próxima refeição é que pode começar a se 
preocupar com o ambiente. Se quisermos que uma floresta permaneça intocada, essa será uma grande vantagem para muitos animais, mas uma oportunidade perdida para plantar comida."

"O que deve nortear as decisões que afetam o meio ambiente são os direitos dos seres humanos, e não dos animais. As pessoas debatem e participam dos processos decisórios, enquanto pingüins e pinheiros não. Logo, o nível de proteção que essas espécies receberão vai depender das pessoas que falam em nome delas. E como algumas pessoas vão valorizar mais algumas plantas e animais, esses não podem receber direitos especiais em detrimento do direito de outros seres humanos. Isso pode parecer egoísta da parte do homem, mas é importante notar que essa visão antropocêntrica não consiste automaticamente em negligenciar ou eliminar outras formas de vida. Os homens são tão dependentes de outros seres vivos que muitas espécies terão o seu bem-estar garantido." $* * *$

"Se eu pudesse escolher o melhor ambiente para viver, teria nascido agora mesmo ou um pouco mais no futuro. As pessoas se imaginam vivendo num ambiente intocável na pré-história, mas esquecem que a média de vida por lá era de apenas 20 anos. A luta por comida era dura e, muitas vezes, a natureza era nossa inimiga. Somente hoje, quando contamos com a tecnologia para viver, em média, 67 anos, podemos nos preocupar com a preservação. Ao mesmo tempo, somos 6,2 bilhões de pessoas no planeta marchando para 9 bilhões em 2050, o que, certamente, causará problemas. Contudo, acredito que a vida poderá ser melhor." (SUPERINTERESSANTE, jul. 2002.)

Foram considerados bons os textos com as seguintes características: a) Adequação ao gênero "resumo", com seleção das informações mais relevantes que estão distribuídas nas partes do texto fonte e sua exposição em um novo texto, de forma clara e articulada. O texto fonte faz uma apresentação de B. Lomborg (estatístico, dinamarquês etc.) e expõe suas opiniões polêmicas sobre algumas questões amplamente debatidas pelos ambientalistas (avaliação das condições do meio ambiente na atualidade, definição de prioridades na preservação das florestas e de espécies vegetais e animais ameaçados de extinção). Um bom resumo deve ter contemplado tanto a apresentação de Lomborg quanto de suas opiniões; b) Fidelidade e isenção ao 
WACHOWICZ, T. C. et. al. O que está atrás da avaliação...

expor as informações. O candidato deve revelar uma boa leitura do texto e apresentar as opiniões de Lomborg, atribuindo-lhe adequadamente a autoria das afirmações, sem mesclá-las com comentários pessoais. O texto 4, abaixo, por exemplo, ficou com conceito bom e nota 5:

Conforme o texto retirado da Superinteressante, o livro publicado por Bjorn Lomborg vem despertando críticas pesadas dos ambientalistas. Em sua obra, Lomborg afirma que não há a necessidade de preocupação com os desastres ambientais que vêm ocorrendo, pois, segundo ele, o ambiente global está bem e só tende a melhorar. Em suas declarações, ele defende que não é racional nos preocuparmos com animais e florestas enquanto há milhões de pessoas passando fome. Lomborg também admite que enxerga problemas em função do crescimento acelerado da população, mas que, mesmo assim, se dependesse dele, escolheria nascer agora ou mais adiante, quando, segundo o autor, a vida será ainda melhor.

Texto 4: redação prototípica para o conceito BOM, nota 5, da questão 22.

Por outro lado, foram considerados nulos os textos que não atenderam minimamente ao que foi solicitado no enunciado da questão. São casos em que os candidatos não elaboraram um resumo, como foi solicitado, mas um texto sobre a questão do meio ambiente ou outro tema qualquer:

A vida é, sem dúvida, preciosa. O ser humano tem um valor inestimável. Não há comparação entre o homem e o leão. Porém deve se ter cuidado ao mandar certos recados. A produção de alimentos é suficiente no momento, o que está errado é distribuição do arrecadado. Pessoas estão morrendo porque o outro tem dinheiro e pode comprar arroz e feijão, mas o pobre coitado nada tem para um pão. Florestas são queimadas, animais entram em extinção, a poluição cresce a cada ano e o problema não é a alimentação. É como viver em um mundo onde não há mais árvores, onde a camada de 
ozônio foi destruída e a indústria modernizada para uma nação que não tem arroz nem feijão?

Texto 5: redação prototípica para o conceito NULO, da questão 22.

O texto com conceito regular revelava compreensão do texto fonte, com fidelidade na exposição parcial das informações. Os comentários pessoais mesclados à exposição das afirmações extraídas do texto, bem como problemas de fluência de texto escrito balizavam o conceito regular para cima ou para baixo. O texto 6, por exemplo, exemplifica um caso de conceito regular, que manteve a nota 3 :

Best-seller de Bjorn Lomborg, "O ambientalista cético" causa polêmica entre ambientalistas. $\mathrm{O}$ dinamarquês revela que não há necessidade de alarme ambiental. Ele ainda critica de maneira negativa os ecologistas que cultivam o pânico. Diz que há problemas sociais mais sérios a serem resolvidos pela humanidade. O estatístico dinamarquês valoriza os direitos humanos, colocando o homem como o ser de maior valia, porém não tira a importância dos outros animais. Faz uma comparação histórica da qualidade e prova que está em boa época para viver, porém "poderá ser melhor."

Texto 6: redação prototípica para o conceito REGULAR, com nota 3, da questão 22.

\section{Questão 23}

A questão 23 ficou com o aspecto "divertido" da prova. Ela solicitou ao candidato um texto de divulgação, a ser publicado em jornal, sobre a reforma e os serviços de uma oficina mecânica. A proposta baseou-se na foto de uma fachada de oficina em que se anunciavam, em escrita nãopadrão, os serviços prestados: 


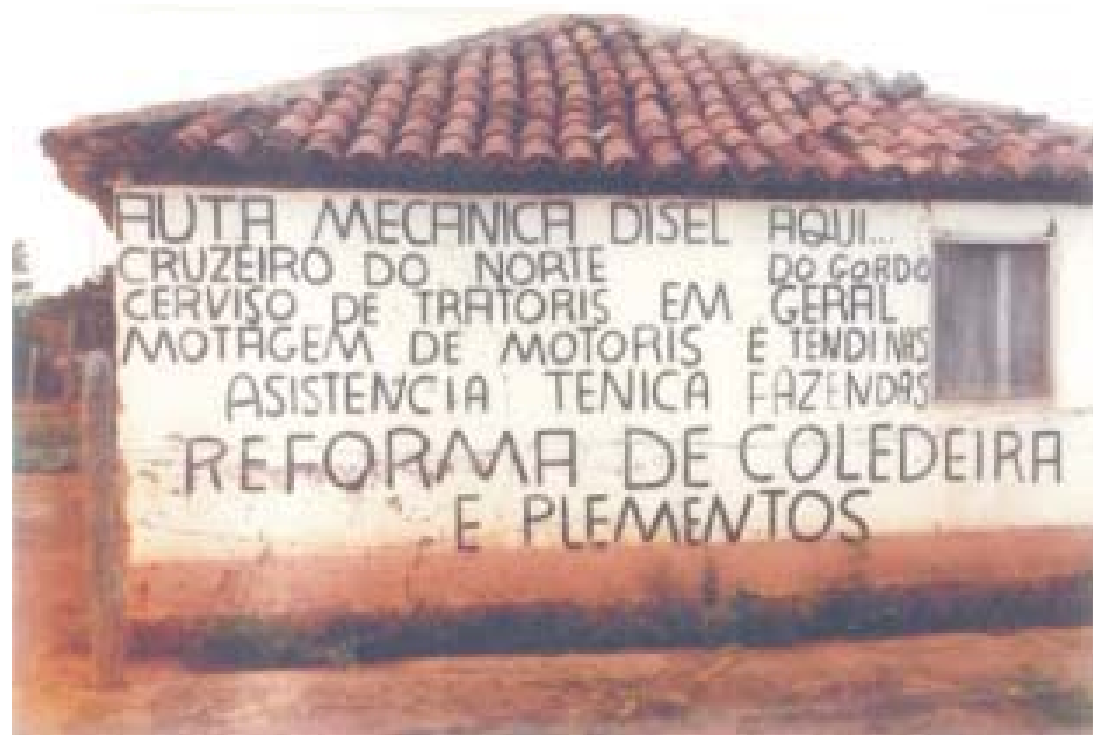

O mecânico José Pereira, proprietário da oficina da foto acima, decidiu fazer uma reforma de seu estabelecimento, que, além dos serviços já anunciados na pintura da parede, passará a fazer também consertos de caminhões. A divulgação dos serviços prestados passará a ser feita através de um texto publicado no jornal local, melhorando com isso a imagem da oficina.

23 - Escreva um texto de até 10 linhas para a divulgação dos serviços prestados pela oficina mecânica, que deve incluir não só os já anunciados na parede mas também a notícia da reforma e da nova atividade. O texto, para ser publicado no jornal, deve ser redigido segundo as normas do português padrão escrito.

A equipe desta questão valorizou o grau de complexidade envolvido na solução escolhida pelo candidato: as informações - de reforma e serviços - deveriam ser acompanhadas de recursos apelativos refinados e criativos, próprios de um texto de divulgação publicitária (ABAURRE; PONTARA 2002), além de domínio da norma padrão. O texto 7 , abaixo, responde a essas características: 
Com o objetivo de atender da melhor maneira possível e de ampliar o número de clientes, José Pereira, proprietário da auto-mecânica Diesel, em Cruzeiro do Norte, promoveu uma grande reforma em seu estabelecimento. Agora, além dos serviços anteriormente prestados: assistência técnica para motores e tratores, reforma de colheitadeiras e atendimento nas fazendas da região; a oficina passará a fazer também consertos de caminhões. Dessa maneira, a auto-mecânica Diesel espera agradar a todos os clientes com instalações mais moderadas e serviços eficientes.

Texto 7: redação prototípica para o conceito BOM, com nota 5, da questão 23.

Já o conceito de texto insuficiente ficou por conta, principalmente, da ausência das informações que constituem o foco da questão, além de extensão insuficiente do texto ou ocorrência de desvio da norma padrão:

O mecânico José Pereira, proprietário de uma oficina, está divulgando seu estabelecimento. Seu José conserta tratores em geral, monta motores, da assistência tecnicas de fazendas e reforma geladeiras.A melhor oficina que trata muito bem você e seus eletrodoméstico motores em geral e até fazendas, agora também passará a fazer consertos de caminhões. Se você precisa de ajuda para algum conserto vá até a oficina do José Pereira.

Texto 8: redação prototípica para o conceito INSUFICIENTE, com nota 1 , da questão 23 .

$\mathrm{O}$ conceito regular, atribui-se a textos que cumprem regularmente a tarefa, com relativa adequação nos aspectos formais, mas sem arrojamento na escolha de tipo textual. Não há no texto precisão suficiente das informações, ou falta coesão para que se evidendie o enfoque do texto nas novidades da oficina. A presença de um desvio grave da norma padrão, ainda que pontual, determina que a nota não se eleve a quatro. É o caso do texto 9 abaixo: 
WACHOWICZ, T. C. et. al. O que está atrás da avaliação...

Venha consertar sua máquina na auto mecânica Cruzeiro do Norte. Oferecemos conserto e assistência técnica em tratores e caminhões e reformas em colhedeiras. Agora cm novas instalações. Também fazemos montagem de motores. Atendemos na sua fazenda.

Texto 9: redação prototípica para o conceito REGULAR, com nota 3, da questão 23 .

\section{Questão 24}

Por fim, a questão 24 voltou-se a uma das obras da lista de literatura: Esaú e Jacó, de Machado de Assis. A questão pedia que o candidato relacionasse uma passagem do romance a elementos de seu enredo como um todo. Selecionar os elementos pertinentes para tratar do problema colocado pelo enunciado e construir um texto argumentativo que sustentasse o acerto da observação feita pelo narrador eram as habilidades requeridas pela questão:

24 - Leia o trecho abaixo, extraído do capítulo "Troca de Opiniões", do romance Esaú e Jacó, escrito por Machado de Assis.

Senão quando, viu Natividade os primeiros sinais de uma troca de inclinação, que mais parecia propósito que efeito natural. Entretanto, era naturalíssimo. Paulo entrou a fazer oposição ao governo, ao passo que Pedro moderava o tom e o sentido, e acabava aceitando o regime republicano, objeto de tantas desavenças.

Num texto de no máximo dez linhas, explique por que o narrador tem razão ao dizer que essa mudança não é algo proposital, mas sim natural, para os gêmeos.

Para que seu texto fosse considerado bom, o candidato deveria dar uma resposta efetiva à questão, explicando com argumentos consistentes e pertinentes, e sem cair em contradição, que o narrador está certo ao afirmar que é natural a mudança pela qual os gêmeos passam. Deveria estabelecer, ainda que sumariamente, uma articulação entre os níveis psicológico 
- as características das personagens Pedro e Paulo - e social ou político a transição da monarquia para a república - da narrativa. É o que se observa no texto 10 , que obteve conceito bom com nota 5 :

A mudança é fato natural por uma razão bastante simples: Paulo, tendo espírito revolucionário e sede de mudança, nunca se dá por satisfeito, estando sempre disposto a atacar os defeitos do sistema vigente, na esperança de aprimorá-lo: Logo, ainda que defendesse a república durante a monarquia, quando aquela se instaura, vê problemas que podem e devem ser resolvidos. Já Pedro carrega na alma o desejo de estabilidade e segurança. Teme mudanças e revoluções por duvidar de sua consistência. Uma vez que a república se prova regime estável e funcional, Pedro prefere defendêla e estagnar-se a tentar mudá-la e correr riscos.

Texto 10: redação prototípica para o conceito BOM, com nota 5, da questão 24.

Foi considerado insuficiente, aqui, aquele texto que, embora revele algum conhecimento sobre Esaú e Jacó, não traz elementos relacionados à oposição que está na base da questão proposta, ou, fazendo uma leitura equivocada do trecho citado, enxerga uma aproximação entre os irmãos que em tudo se opunham.

Meras paráfrases das informações contidas no enunciado, assim como resumos genéricos do enredo, que não revelem trabalho de seleção de elementos ligados à oposição entre os gêmeos, também são considerados insuficientes. Esse é o caso do texto 11:

Paulo é liberal e é a favor da democracia, enquanto seu irmão Pedro é conservado e a favor da monarquia. Apesar de Pedro e Paulo serem irmãos gêmeos e brigarem muito durante toda a história do livro, tendo apenas alguns momentos de reconciliação, eles algumas vezes repartem da mesma opinião, como no caso de Pedro gostar de algumas idéias objetivadas pela democracia. Esse não é o único caso durante a história do livro, pois mesmo sendo irmãos e rivais e perfeitamente possível duas pessoas terem a mesma idéia. 
Texto 11: redação prototípica para o conceito INSUFICIENTE, com nota 1 , da questão 24 .

Para que seu texto fosse considerado regular, o candidato deveria evidenciar a relação de oposição entre Pedro e Paulo, compatível com a mudança de que trata o enunciado, e escolher elementos da narrativa que sustentem argumentativamente a natureza dessa oposição. Um texto que seja um resumo do livro poderá ser considerado regular se os elementos que o constituírem enfatizarem a relação de oposição.

No texto 12 , abaixo, com conceito regular e nota 2 , o candidato não chegou a dar uma resposta à questão proposta, nem sequer tocando na mudança de posicionamento que lhe serve de base. Por outro lado, demonstrou ter compreendido bem as oposições entre os gêmeos, mencionando elementos da narrativa pertinentes para caracterizar essa oposição. Além disso, fez boa seleção de elementos, já que, no final do texto, esboça, pelo menos em relação a Paulo, aquele traço psicológico que serve de explicação para sua atitude de fazer oposição ao regime republicano que antes tão enfaticamente defendera:

Ainda no ventre de Natividade os gêmeos Pedro e Paulo brigavem, e na infância já notava-se a diferença de personalidade e a rivalidade existente entre ambos, que nem mesmo a idade adulta conseguiu amenizar. Pois enquanto Pedro, que era monarquista e portanto conservador, optou por estudar medicina, seu irmão Paulo, que era republicano, resolver fazer direito.Dos gêmeos, Paulo era considerado de certa forma um rebelde, pois sempre fazia oposição a tudo e a todos.

Texto 12: redação prototípica para o conceito REGULAR, com nota 2, da questão 24 . 


\section{Comentários estatísticos}

Além da análise de critérios lingüísticos exemplificados nos textos prototípicos listados acima, é importante observar que os objetivos avaliativos de uma correção de textos de vestibular acompanha, necessariamente, monitoramento estatístico. Novamente, frisamos que a situação de correção de vestibular distingue-se da correção de sala de aula: há tanto aspectos qualitativos quanto quantitativos a serem considerados.

O quadro 1, abaixo, apresenta as médias de cada uma das questões. Como se pode observar, as três primeiras questões (21, 22 e 23) apresentaram médias muito próximas, o que revela níveis de dificuldade semelhantes entre si.

A questão 24, por outro lado, destacou-se das demais pela dificuldade. Nessa questão, além do domínio das normas de escrita, o candidato tinha também que demonstrar conhecimentos de um dos livros que constavam da lista prevista para o processo seletivo. A falta desses conhecimentos fez com que muitos candidatos deixassem a questão em branco ou a respondessem com informações inadequadas.

A média geral da prova de redação foi de 2,52, em uma escala de 0 a 6, o que representa 4,20 após a conversão para a escala de 0 a 10.

Quadro 1- médias das questões da prova de Redação - 2003

Dados sobre as médias das questões e sobre as médias das notas atribuídas pelos corretores individualmente fizeram parte do monitoramento realizado durante todo o processo de correção. O acompanhamento das

QUADRO 1 - MÉDIAS DAS QUESTÕES DA PROVADE REDAÇÃO - 2003

\begin{tabular}{|c|c|}
\hline questão & média \\
\hline 21 & $\mathbf{2 , 7 5 7}$ \\
\hline 22 & $\mathbf{2 , 6 8 2}$ \\
\hline 23 & $\mathbf{2 , 8 0 1}$ \\
\hline 24 & $\mathbf{2 , 0 2 5}$ \\
\hline
\end{tabular}


médias (mesmo com eventual variação de qualidade entre diferentes lotes de redação) foi um dos instrumentos utilizados para monitorar como critérios discutidos pelas equipes estavam sendo observados na prática.

Além de dados sobre as médias, foram também gerados periodicamente relatórios indicativos da dispersão das notas atribuídas. Com essa informação, era possível ter um indicativo de como os corretores e as equipes encarregadas de cada questão estavam fazendo uso das várias categorias da escala para discriminar as redações dos candidatos.

\section{Conclusão}

Face aos problemas inerentes a qualquer correção de redações de larga escala, como as discrepâncias entre as avaliações dos corretores, as interferências subjetivas na atribuição de notas, a impossibilidade de convergência absoluta de notas em um número grande de corretores etc., a correção das redações do processo seletivo de 2003, em contrapartida, trouxe resultados metodológicos interessantes. A adoção de uma escala de 0 a 6, no lugar da escala convencional de 0 a 10, a definição de critérios por amostragem, acompanhada de discussões constantes entre os corretores, mas sobretudo a clareza de critérios definidos com a autonomia de cada equipe, trouxeram inegavelmente maior segurança - partilhada - ao momento de atribuição de notas. Esperamos que nosso relato de trabalho possa ter esclarecido algumas dúvidas e curiosidades sobre a correção das redações da UFPR. Se ele ajudou em algum sentido o leitor que trabalha com o assunto, nosso objetivo é então duplamente atendido. 


\section{REFRÊNCIAS}

ABAurRe, M. L.; PONTARA, M. N. Português. São Paulo: Moderna, 2002.

BRANDÃO, H. N. (Coord.). Gêneros do discurso na escola. São Paulo: Cortez, 1999. v. 5.

FÁVERO, L. L. Coesão e coerência textuais. 3. ed. São Paulo: Ática, 1995.

KOCH, I. G. V. A coesão textual. 17. ed. São Paulo: Contexto, 2002.

A coerência textual. 17. ed. São Paulo: Contexto, 2002.

MEC/SEF. Parâmetros Curriculares Nacionais - Língua Portuguesa - Ensino Médio. Brasília: MEC, 1999.

PERELMAN, C.; OLBRECHTS-TYTECA, L. Tratado da argumentação a nova retórica. São Paulo: Martins Fontes, 1996.

PLATÃO, F.; FIORIN, J. L. Para entender o texto - leitura e redação. 7. ed. São Paulo: Ática, 1993. 